\title{
UJI EFEKTIVITAS BERBAGAI ISOLAT MIKORIZA INDIGENUS DAN BAHAN ORGANIK TERHADAP PERTUMBUHAN KOPI ROBUSTA DI DATARAN TINGGI
}

\author{
Ardi Sardina Abdulah ${ }^{1}$, Syafrison ${ }^{2}$, dan Fardedi ${ }^{2 *}$ \\ ${ }^{*}$ Program Studi Pengelolaan Perkebunan, Jurusan Budidaya Tanaman Perkebunan \\ Politeknik Pertanian Negeri Payakumbuh \\ ${ }^{* 2}$ Program Studi Budidaya Tanaman Perkebunan, Jurusan Budidaya Tanaman Perkebunan \\ Politeknik Pertanian Negeri Payakumbuh
}

Korespondesi : datuk.syafrison@gmail.com

\author{
Diterima : 28 Februari 2020 \\ Disetujui : 25 Agustus 2020 \\ Diterbitkan : 31 Agustus 2020
}

\begin{abstract}
ABSTRAK
Lahan perkebunan kopi rakyat di Sumatera Barat sebagian telah terdegradasi baik secara fisik, kimia dan biologi sehingga terdapat beberapa faktor pembatas dalam pemanfaatannya seperti; $\mathrm{pH}$ rendah, Kapasitas Tukar Kation rendah, bahan organik rendah, kandungan $\mathrm{P}$ yang sangat rendah, dan kandungan $\mathrm{Al}$ cukup tinggi yang dapat meracuni pertumbuhan tanaman. Usaha perbaikan sifat fisik, dan kimia sudah banyak dilakukan, namun hasil yang diperoleh belum optimal. Oleh karenanya perlu perbaikan secara biologi dengan memanfaatkan bahan organik setempat dan Fungi Mikoriza Arbuskula indigenus. Pada lahan perkebunan kopi terdapat Fungi Mikoriza Arbuskula indigenus yang berpotensi dapat ditingkatkan efektifitasnya dan diproduksi dalam berbagai bentuk inokulan sehingga dapat digunakan sebagai pupuk hayati (biofertilizer). Potensi utama Fungi Mikoriza Arbuskular (FMA) dapat membantu penyerapan hara yang lebih baik oleh tanaman, meningkatkan resistensi tanaman terhadap kekeringan, hama penyakit, logam berat, bersifat sinergis dengan mikroba lain serta berperan aktif dalam siklus hara dan meningkatkan stabilitas ekosistem. Penelitian ini telah dilaksanakan di lahan perkebunan kopi rakyat di Dataran Tinggi, Kabupaten Tanah Datar. Penelitian menggunakan rancangan acak kelompok terdiri dari 6 perlakuan, dan satu perlakuan 4 tanaman. Setiap kombinasi perlakuan diulang 3 kali sehingga diperoleh 3 × $6=18$ satuan percobaan. Data penelitian hasil pengamatan diuji dengan analisis ragam dan jika perlakuan penunjukkan pengaruh yang nyata, maka dilanjutkan dengan DNMRT pada taraf kepercayaan 95\%. Hasil penelitian menunjukkan bahwa perlakuan bahan organik dan mikoriza Mycoper $\left(\mathrm{B}_{1} \mathrm{M}_{2}\right)$ berpengaruh lebih baik dibandingkan dengan lainnya. Demikian juga pengaruh bahan organik, dengan kombinasi mikoriza menunjukkan pengaruh yang lebih baik, bila dibandingkan bahan organik tanpa pemberian mikoriza ( $\mathrm{B}_{1}$ $\left.\mathrm{M}_{0}\right)$.
\end{abstract}

Kata Kunci: Mikoriza, bahan organik, lahan perkebunan kopi 


\title{
I.UMIBUNG
}

\begin{abstract}
Some people's coffee plantations in West Sumatra have been degraded both physically, chemically and biologically so that there are some limiting factors in their use such as; low $\mathrm{pH}$, low cation exchange capacity, low organic matter, very low P content, and high Al content that can poison plant growth. Efforts to improve physical and chemical properties have been carried out, but the results obtained are not optimal. Therefore it is necessary to improve biologically by utilizing local organic material and the fungus Arbuscular indigenus. On the coffee plantation land there is the Arbuscular Indigenus Mycorrhizal Fungi which can potentially be increased in effectiveness and produced in various forms of inoculants so that it can be used as a biofertilizer. The main potential of Arbuscular Mycorrhizal Fungi (FMA) can help better nutrient absorption by plants, increase plant resistance to drought, disease pests, heavy metals, are synergistic with other microbes and play an active role in the nutrient cycle and increase ecosystem stability. The research has been conducted on the people's coffee plantation land in the Highlands, Tanah Datar District. The study used a randomized block design consisting of 6 treatments, and one treatment 4 plants. Each treatment combination was repeated 3 times to obtain $3 \times 6=18$ experimental units. Observational research data were tested by analysis of variance and if the treatment showed a real effect, then continued with DNMRT at $95 \%$ confidence level. The results showed that the treatment of organic matter and mycoper mycorrhiza (B1 M2) had a better effect than others. Likewise, the effect of organic matter, with the combination of mycorrhiza shows a better effect, when compared to organic matter without the administration of mycorrhiza (B1 MO).
\end{abstract}

Keywords: Mycorrhizae, organic materials, coffee plantation land

\section{PENDAHULUAN}

Sumatera Barat merupakan salah satu sentra penghasil komoditi kopi di Indonesia. Namun demikian lahan perkebunan kopi rakyat di Sumatera Barat sebagian telah terdegradasi baik secara fisik, kimia dan biologi sehingga terdapat beberapa faktor pembatas dalam pemanfaatannya seperti; pH rendah, Kapasitas Tukar Kation rendah, bahan organik rendah, kandungan $\mathrm{P}$ yang sangat rendah, dan kandungan Al cukup tinggi yang dapat meracuni pertumbuhan tanaman. Untuk mengatasi masalah ini perlu cara yang efektif dan bersahabat dengan lingkungan dalam rangka mewujudkan sistem pertanian berkelanjutan.

Di Sumatera Barat luas lahan yang dapat dimanfaatkan untuk pertanian adalah 785.458 hektar yang terdiri dari 4.259 ha sangat sesuai (S1), 781.189 hektar kurang sesuai (S3) dan tergolong kritis mencapai 267.000 hektar (BPS, 2005). Tanah yang 
luas ini secara umum mempunyai potensi yang cukup besar untuk perluasan dan peningkatan hasil tanaman kopi.

Karena usaha peningkatan pertumbuhan dan hasil tanaman kopi pada lahan perkebunan kopi di Sumatera Barat, memiliki beberapa faktor pembatas antara lain seperti yang telah diuraikan di atas, maka oleh karena itu dalam usaha pengelolaannya diperlukan Fungi Mikoriza Arbuskula (FMA) yang efektif. Banyak hasil penelitian yang menunjukkan cendawan ini mampu mengatasi permasalahan fisik, kimia dan biologi tanah.

Penelitian ini diharapkan memberi sumbangan untuk pengembagan ilmu pengetahuan, pengembangan teknologi budidaya tanaman kopi dan mendukung pemerintah dalam menyediakan pupuk hayati (Inokulum FMA spesifik tanaman kopi) menuju sistem pertanian berkelanjutan.

Dari uraian di atas maka dapat diringkas pentingnya penelitian tahun pertama dan kedua ini sebagai berikut :

1. Isolat Fungi Mikoriza Arbuskula yang sudah didapatkan perlu diuji efektivitas-nya

2. Perlu diuji penambahan bahan organik terbaik terhadap peningkatan produktivitas lahan perkebunan dan pertumbuhan tanaman kopi.

Hasil penelitian sebelumnya di Dataran Sedang (300-500 m dpl), menunjukkan bahwa pengaruh mikoriza lokal pemperlihatkan pertumbuhan tanaman kopi yang terbaik pada perlakuan Isolat FMA indigenus 10 gr per tanaman, sedangkan pengaruh bahan organik tidak menunjukkan pengaruh.

Berkaitan dengan masalah di atas perlu dilakukan penelitian mengenai keragaman dan potensi Fungi Mikoriza Arbuskular (FMA) indigenus untuk mendapatkan pupuk hayati FMA yang dapat meningkatkan efisiensi pemupukan dan pertumbuhan serta hasil tanaman kopi rakyat pada elevasi atau ketinggian yang berbeda.

Tujuan khusus yang ingin diperoleh dalam penelitian ini adalah untuk mengetahui pengaruh efektifitas isolat fungi mikoriza arbuskula dan bahan organik setempat dalam meningkatkan pertumbuhan kopi di Dataran Tinggi (600-1000 m dpl) Sumatera Barat.

\section{METODE PENELITIAN}

Percobaan ini dilakukan di salah satu kebun kopi rakyat di Jorong Koto Sibauk, Nagari Tanjung Alam, Kecamatan Tanjung Baru, Kabupaten Tanah Datar, Sumatera 


\section{I.UMIBUNG}

Barat, yang merupakan dataran tinggi dengan ketinggian $660 \mathrm{~m}$ dpl. Selama 5 bulan dari Bulan Juli 2019 sampai Desember 2019.

Bahan yang digunakan adalah bibit kopi robusta berumur 4 - 6 bulan dari kebun rakyat di Kabupaten 50 Kota, yang sudah diberi inokulum mikoriza indigenus terpilih sebanyak 10 g pertanaman. Pupuk kandang $2 \mathrm{~kg} / \mathrm{tanaman}$, dan pupuk Urea, SP36, serta $\mathrm{KCl}$. Selain itu polibag besar $(40 \mathrm{~cm} \times 50 \mathrm{~cm})$, papan nama, dan ajir. Alat yang dipergunakan berupa cangkul, parang, sekop, dan alat budidaya lainnya.

\section{a. Rancangan percobaan}

Rancangan percobaan yang digunakan pada penelitian ini adalah Rancangan Acak Kelompok. Setiap kombinasi perlakuan diulang 3 kali, setiap satuan percobaan ada 4 tanaman. Sehingga diperoleh 4 × 6 × $3=72$ tanaman, kombinasi perlakuan pada Gambar 1 :

\begin{tabular}{|c|c|c|}
\hline $\mathbf{B}_{\mathbf{0}} \mathbf{M}_{\mathbf{0}}$ & $\mathbf{B}_{0} \mathbf{M}_{1}$ & $\mathbf{B}_{1} \mathbf{M}_{0}$ \\
\hline $\mathbf{B}_{0} \mathbf{M}_{1}$ & $\mathbf{B}_{\mathbf{0}} \mathbf{M}_{\mathbf{0}}$ & $\mathbf{B}_{0} \mathbf{M}_{2}$ \\
\hline $\mathbf{B}_{0} \mathbf{M}_{2}$ & $\mathbf{B}_{1} \mathbf{M}_{2}$ & $\mathbf{B}_{0} \mathbf{M}_{0}$ \\
\hline $\mathbf{B}_{1} \mathbf{M}_{0}$ & $\mathbf{B}_{\mathbf{0}} \mathbf{M}_{2}$ & $\mathbf{B}_{1} \mathbf{M}_{1}$ \\
\hline $\mathbf{B}_{1} \mathbf{M}_{1}$ & $\mathbf{B}_{1} \mathbf{M}_{0}$ & $\mathbf{B}_{1} \mathbf{M}_{2}$ \\
\hline $\mathbf{B}_{1} \mathbf{M}_{2}$ & $\mathbf{B}_{1} \mathbf{M}_{1}$ & $\mathbf{B}_{0} \mathbf{M}_{1}$ \\
\hline
\end{tabular}

Keterangan :

$\mathbf{B}_{0} \quad$ : Tanpa pupuk kandang $\left(0 \mathrm{~kg} \operatorname{tanaman}^{-1}\right)$

$\mathbf{B}_{1} \quad$ : Pupuk kandang $\left(2 \mathrm{~kg} \operatorname{tanaman}^{-1}\right)$

$\mathbf{M}_{\mathbf{0}} \quad$ : Tanpa isolat FMA

$\mathbf{M}_{\mathbf{1}}$ : Isolat FMA indigenus (10 $\left.\mathrm{gr} \mathrm{tanaman}^{-1}\right)$

$\mathbf{M}_{2}$ : Isolat FMA Mycoper (FMA introduksi : asal Bogor)

Gambar 1. Denah Penelitian

\section{b. Persiapan lahan dan pemberian pupuk kandang}

Lahan yang akan digunakan dibersihkan terlebih dahulu dari semak belukar. Setelah itu dilakukan pengajiran untuk menempatkan polibag. Letak dan susunan petak tanaman diatur berdasarkan denah yang sudah dirancang.

Pupuk kadang kering-udara ditimbang berdasarkan dosis $2 \mathrm{~kg} / \mathrm{tanaman}$, diaduk dengan tanah, selanjutnya dimasukkan dalam polibag besar. 


\section{c. Penanaman dan pemeliharaan}

Penanaman bibit dilakukan dengan terlebih dahulu memotong polibag kecil di bagian bawah sampai keujung, kemudian bibit dikeluarkan dari polibag dengan hati-hati agar per perakaran tidak rusak. Masukkan bibit ke dalam polibag besar yang sebelumnya di buat lubang tanam sedalam 7-10 cm, dan masukkan sisa tanah yang ada dipermukaan ke dalam lubang, lalu dipadatkan.

Pemeliharaan tanaman meliputi penyiangan, dan pemupukan. Penyiangan dilakukan sekali dalam 2 minggu pada tanah disekitar tanaman dan memperbaiki drainase. Pupuk dasar Urea $22 \mathrm{~g} / \operatorname{tanaman}$, SP36 $25 \mathrm{~g} / \operatorname{tanaman}$ dan $20 \mathrm{~g} / \operatorname{tanaman} \mathrm{KCl}$, diberikan secara melingkar, di ujung sebelah dalam polibag sedalam $7-10 \mathrm{~cm}$ bersamaan dengan waktu tanam.

\section{d. Peubah yang diamati}

Uji isolat mikoriza dan pupuk kandang terhadap serapan hara dan pertumbuhan kopi di lakukan terhadap peubah :

1). Tinggi tanaman $(\mathrm{cm})$; diukur dari pangkal batang hingga pangkal tangkai daun terakhir. Pengukuran ini dilakukan pada umur 2, 4, 6, dan 8 minggu setelah penanaman, kemudian dihitung rata-rata selisih pertumbuhannya.

2) Bobot tajuk (g); diukur setelah tanaman dipanen dengan cara memotong seluruh bagian diatas pangkal akar

\section{e. Analisis Data}

Data penelitian hasil pengamatan diuji dengan analisis sidik ragam.

\section{HASIL DAN PEMBAHASAN}

Hasil penelitian menunjukkan bahwa pengaruh mikoriza lokal/setempat yang diambil dari daerah zona perakaran pertanaman kopi memperlihatkan rata-rata selisih pertumbuhan tanaman kopi robusta interval 2 (dua) minggu di dataran tinggi, sebagai berikut :

(1). Pada perlakuan bahan organik dan mikoriza Mycoper $\left(B_{1} M_{2}\right)$ berpengaruh lebih baik dibandingkan dengan lainnya.

(2). Hal lain, menunjukkan bahwa pengaruh bahan organik, dengan kombinasi mikoriza menunjukkan pengaruh yang lebih baik, bila dibandingkan bahan organik tanpa pemberian mikoriza ( $\left.\mathrm{B}_{1} \mathrm{M}_{0}\right)$, Tabel 1 dan 2 . 


\section{I.UMIBUNC}

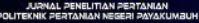

Tabel 1.Analisis selisih pertumbuhan $(\mathrm{cm})$

\begin{tabular}{ccl}
\hline PERLAKUAN & \multicolumn{2}{l}{ RATA-RATA } \\
\hline $\mathrm{B}_{1} \mathrm{M}_{0}$ & 0.80 & $\mathrm{a}$ \\
\hline $\mathrm{B}_{0} \mathrm{M}_{2}$ & 0.81 & $\mathrm{a}$ \\
\hline $\mathrm{B}_{0} \mathrm{M}_{0}$ & 0.83 & $\mathrm{a}$ \\
\hline $\mathrm{B}_{0} \mathrm{M}_{1}$ & 0.85 & $\mathrm{a}$ \\
\hline $\mathrm{B}_{1} \mathrm{M}_{1}$ & 1.09 & $\mathrm{a}$ \\
\hline $\mathrm{B}_{1} \mathrm{M}_{2}$ & 1.41 & $\mathrm{ab}$ \\
\hline
\end{tabular}

Tabel 2. Analisis selisih bobot kering (gr)

\begin{tabular}{crl}
\hline PERLAKUAN & \multicolumn{2}{l}{ RATA-RATA } \\
\hline $\mathrm{B}_{1} \mathrm{M}_{0}$ & 1.0717 & $\mathrm{a}$ \\
\hline $\mathrm{B}_{0} \mathrm{M}_{2}$ & 1.3208 & $\mathrm{ab}$ \\
\hline $\mathrm{B}_{0} \mathrm{M}_{0}$ & 1.5383 & $\mathrm{ab}$ \\
\hline $\mathrm{B}_{0} \mathrm{M}_{1}$ & 1.7367 & $\mathrm{ab}$ \\
\hline $\mathrm{B}_{1} \mathrm{M}_{1}$ & 1.7667 & $\mathrm{ab}$ \\
\hline $\mathrm{B}_{1} \mathrm{M}_{2}$ & 1.8183 & $\mathrm{~b}$ \\
\hline
\end{tabular}

Hal tersebut di atas sesuai dengan hasil penelitian Abdulah, SA dan Syafrison (2016) yang menyatakan bahwa : Isolat mikoriza lokal LK II (Glomus $\mathrm{sp}_{1+}$ Glomus $\mathrm{sp}_{2}+$ Glomus $\mathrm{sp}_{3}+$ Glomus $\mathrm{sp}_{5}+$ Gigaspora $\mathrm{sp} 1+$ Scutelospora $\mathrm{sp}_{1}$ ) dengan tanaman inang Peuraria Javanica mempunyai persentase infeksi yang paling tinggi $(95,17 \%)$ menyusul tanaman sorgum $(87,47 \%)$ dan tanaman inang jagung $(83,93 \%)$.

Selanjutnya dikatakan, Abdulah, A.S., Syafrison, Fardedi, Soemarsono dan Synthia O.G.A. (2019), di Dataran Sedang (300-500 m dpl), bahwa pengaruh mikoriza lokal (LK II), memperlihatkan pertumbuhan tanaman kopi yang terbaik pada perlakuan Isolat FMA indigenus 10 gr per tanaman, sedangkan bahan organik tidak menunjukkan pengaruh.

Pendapat lai menurut Zarate, dan Cruz, (1995) bahwa keefektifan mikoriza berbeda untuk setiap tanaman dan kondisi lingkungannya. Hasil penelitian inokulasi FMA pada 
Avena sativa (Khan IA, Ahmad S, Ayub N., 2003) menunjukkan bahwa penyerapan P dapat ditingkatkan dengan adanya FMA. Inokulasi dengan Gigaspora rosea diperoleh serapan P sebesar 0,50\%, Glomes intraradices + Gigaspora $0.75 \%$, dan Glomus etunicatum + Glomus intraradices $0.85 \%$, sedangkan kontrol $0.45 \%$.

\section{KESIMPULAN DAN SARAN}

\section{Kesimpulan}

1. Perlakuan bahan organik dan mikoriza Mycoper $\left(\mathrm{B}_{1} \mathrm{M}_{2}\right)$ berpengaruh lebih baik dibandingkan dengan lainnya.

2. Pengaruh bahan organik, dengan kombinasi mikoriza menunjukkan pengaruh yang lebih baik, bila dibandingkan bahan organik tanpa pemberian mikoriza $\left(\mathrm{B}_{1} \mathrm{M}_{0}\right)$.

\section{Saran}

Perlu adanya penelitian lebih lanjut untuk daerah dataran rendah di Sumatera Barat, untuk melengkapi dua penelitian sebelumnya.

\section{REFERENSI}

Abdulah, A.S., Syafrison, Fardedi, Soemarsono dan Synthia O.G.A. 2019. Uji Efektivitas Berbagai Isolat Mikoriza Indigenus dan Bahan Organik Terhadap Pertumbuhan Kopi Robusta di Dataran Sedang Kabupaten Lima Puluh Kota. Laporan Penelitian. Politeknik Pertanian Negeri Payakumbuh. Tanjung Pati, Kabupaten Lima Puluh Kota.

Abdulah, A.S., dan Syafrison. 2016. Kajian Pemanfaatan Bahan Organik dan mikoriza Indigenus untuk meningkatkan Produktifitas Lahan Perkebunan dan Pertumbuhan Kopi. Laporan Penelitian. Politeknik Pertanian Negeri Payakumbuh. Tanjung Pati, Kabupaten Lima Puluh Kota.

Khan IA, Ahmad S, Ayub N. 2003. Yield and nutrients uptake of Avena sativa as influenced by vesicular arbuscular mycorrhizal (VAM). Asian J. of Plant Sciences, 2(4):373-376.

Muzakkir, 2000. Kajian pemberian pupuk kandang dan Cendawan Mikoriza Arbuskula pada lahan kritis Tanjung Alai Solok terhadap serapan hara P dan hasil tanaman rami (Boehmeria nivea L.Gaud). Politeknik Pertanian Negeri Payakumbuh

Zarate, J.T. and R.E. Dela Cruz, 1995. Pilot testing the effectiveness of arbuscular mycorrhizal fungi in the reforestation of marginal grassland. Biotrop Spec. Publ.No56 : 131-137. Biology and Biotechnology of Mycorrhizae. 